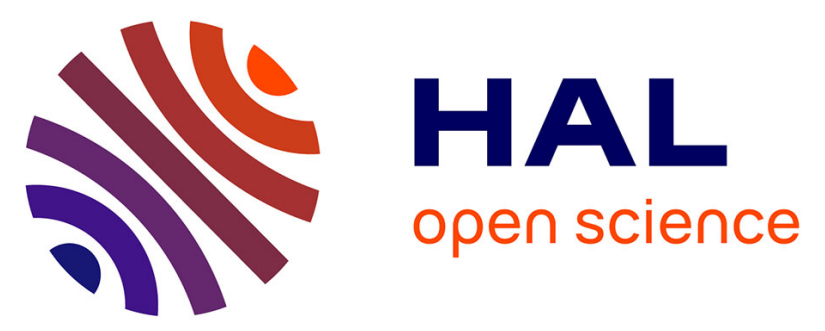

\title{
Prevalence and Risk Factors of Nonalcoholic Fatty Liver Disease and Advanced Fibrosis in General Population: the French Nationwide NASH-CO Study
}

Oumarou Nabi, Karine Lacombe, Jérôme Boursier, Philippe Mathurin, Marie Zins, Lawrence Serfaty

\section{To cite this version:}

Oumarou Nabi, Karine Lacombe, Jérôme Boursier, Philippe Mathurin, Marie Zins, et al.. Prevalence and Risk Factors of Nonalcoholic Fatty Liver Disease and Advanced Fibrosis in General Population: the French Nationwide NASH-CO Study. Gastroenterology, 2020, 159 (2), pp.791-793.e2. 10.1053/j.gastro.2020.04.048 . hal-02975156

\section{HAL Id: hal-02975156 \\ https: / hal.sorbonne-universite.fr/hal-02975156}

Submitted on 15 Dec 2021

HAL is a multi-disciplinary open access archive for the deposit and dissemination of scientific research documents, whether they are published or not. The documents may come from teaching and research institutions in France or abroad, or from public or private research centers.
L'archive ouverte pluridisciplinaire HAL, est destinée au dépôt et à la diffusion de documents scientifiques de niveau recherche, publiés ou non, émanant des établissements d'enseignement et de recherche français ou étrangers, des laboratoires publics ou privés. 


\section{Journal Pre-proof}

Prevalence and Risk Factors of Nonalcoholic Fatty Liver Disease and Advanced Fibrosis in General Population: the French Nationwide NASH-CO Study

Oumarou Nabi, Karine Lacombe, Jerome Boursier, Philippe Mathurin, Marie Zins, Gastroenterology Lawrence Serfaty

PII: S0016-5085(20)30567-9

DOI: $\quad$ https://doi.org/10.1053/j.gastro.2020.04.048

Reference: $\quad$ YGAST 63407

To appear in: Gastroenterology

Accepted Date: 23 April 2020

Please cite this article as: Nabi O, Lacombe K, Boursier J, Mathurin P, Zins M, Serfaty L, Prevalence and Risk Factors of Nonalcoholic Fatty Liver Disease and Advanced Fibrosis in General Population: the French Nationwide NASH-CO Study, Gastroenterology (2020), doi: https://doi.org/10.1053/ j.gastro.2020.04.048.

This is a PDF file of an article that has undergone enhancements after acceptance, such as the addition of a cover page and metadata, and formatting for readability, but it is not yet the definitive version of record. This version will undergo additional copyediting, typesetting and review before it is published in its final form, but we are providing this version to give early visibility of the article. Please note that, during the production process, errors may be discovered which could affect the content, and all legal disclaimers that apply to the journal pertain.

(C) 2020 by the AGA Institute 


\section{Prevalence and Risk Factors of Nonalcoholic Fatty Liver Disease and Advanced Fibrosis in General Population: the French Nationwide NASH-CO Study}

*Oumarou $\mathrm{Nabi}^{1}{ }$, ${ }^{*}$ Karine Lacombe ${ }^{1,2}$, Jerome Boursier ${ }^{3,4}$, Philippe Mathurin ${ }^{5}$, Marie Zins, ${ }^{6,7}$ and Lawrence Serfaty ${ }^{8}$

${ }^{1}$ Inserm UMR-S1136, IPLESP, Sorbonne Université, Paris, France

${ }^{2}$ Infectious Diseases Department, Hôpital Saint-Antoine, APHP, Paris, France

${ }^{3}$ HepatoGastroenterology Department, Anger University Hospital, Angers France

${ }^{4}$ HIFIH Laboratory, UPRES EA3859, SFR 4208, Angers University, Angers, France

${ }^{5}$ Liver Unit, CHU Lille, France

${ }^{6}$ UMS 11 Inserm, Versailles-Saint Quentin University, France

${ }^{7}$ Paris University, Paris, France

${ }^{8}$ Hepatogastroenterology Service, Hôpital de Hautepierre, Hôpitaux Universitaires de Strasbourg, France

*Equally contributed

Short Title: Epidemiology of NAFLD in France

Number of words: 1010

Number of page: 8

Number of table: 1

Number of figure: 1

Corresponding Author:

Lawrence Serfaty

Hôpital Hautepierre

Hôpitaux Universitaires de Strasbourg

67000, Strasbourg

France

Email : lawrence.serfaty@chru-strasbourg.fr 


\section{Conflict of interest : nothing to declare for all authors}

\section{Author contributions of manuscript}

ON, KL and LS: study concept and design; acquisition of data; analysis and interpretation of data; drafting of the manuscript; critical revision of the manuscript for important intellectual content; statistical analysis;

JB, PM: analysis and interpretation of data; drafting of the manuscript; critical revision of the manuscript for important intellectual content

MZ: critical revision of the manuscript for important intellectual content; obtained funding;

Abbreviations

NAFLD : Non-Alcoholic Fatty Liver Disease

NASH : Non-Alcoholic SteatoHepatitis

FLI : Fatty Liver Index

$\mathrm{Fl}:$ Forns Index

HBP : high blood pressure

ALT : alanine amino-transferase

GGT : gamma glutamyl-transferase

Key words: Obesity; type 2 diabetes; Fatty Liver Index; Forns Index 
The burden of non-alcoholic fatty liver disease (NAFLD) and advanced fibrosis has not been reported so far at a nationwide level in Europe. According to a metaanalysis, the prevalence of NAFLD in European countries ranged from 4 to 50\%, reflecting the heterogeneity of study populations (1). The French CONSTANCES population-based cohort was designed as a large representative sample for age, gender and socioeconomic status of the French adult population (2). The present study was aimed to assess the prevalence of NAFLD and advanced fibrosis in the CONSTANCES cohort by using non-invasive markers, and to examine risk factors associated with these conditions.

\section{Materials and Methods}

We conducted a cross-sectional study on data at baseline collected from participants included in the CONSTANCES cohort between 2012 and 2018. CONSTANCES is a "generalist" epidemiological cohort designed to be representative of the general French population consisting of a sample of more than 200000 adults aged 18 years and over at baseline, and residing in 21 departments which hold a Health Screening Center (HSC) in France (2, Supplementary Methods). At inclusion, the selected subjects were invited to complete a health and lifestyle questionnaires and to attend a HSC for a comprehensive health examination. Blood samples were made on a venous blood sample after a 12-hour fasting and analyses were performed in the HSC laboratories according to standards common to all.

The fatty liver index (FLI) was chosen as a surrogate marker of NAFLD. According to the literature, subjects with FLI>60 were considered as having NAFLD (3). The Forns index (FI) was chosen for liver fibrosis evaluation. After validation in patients with biopsy proven NAFLD (Supplementary Methods), NAFLD subjects with Fl> 6.9 were considered as having advanced fibrosis (F3/F4).

Details of statistical analysis are available in Supplementary Methods. 


\section{RESULTS}

At the time of analysis, 163,426 subjects had responded to the invitation letter and data were available in 119,150 participants. Socio-demographic characteristics were similar between participants and the overall responders (data not shown). After excluding subjects who withdrawn their consent, had a history of excessive alcohol consumption defined by daily consumption above $30 \mathrm{~g} / \mathrm{d}$ in men and $20 \mathrm{~g} / \mathrm{d}$ in women $(\mathrm{n}=11,618)$, chronic viral hepatitis (1108 HBV, $560 \mathrm{HCV}$ ) or other causes of liver diseases, 102,344 were retained in the final analysis and defined as overall population (Figure S1).

Characteristics of overall population are shown in Table 1 . According to FLI>60, the adjusted prevalence of NAFLD was $18.2 \%$ (95\%Cl 17.9-18.4), which corresponds to $8.491(95 \% \mathrm{Cl} 8.392-8.585)$ million adult people when extrapolated to the general population in metropolitan France. The prevalence of NAFLD was substantially higher among men compared with women $(25.8 \%, 95 \% \mathrm{Cl}$ 25.4-26.2 vs $11.4 \%, 95 \% \mathrm{Cl} 11.1-11.6)$, and increased with age across gender, from $4 \%$ in women aged $18-27$ years to $44.2 \%$ in men aged $68-78$ years (Figure $1 A$ ). According to risk groups, the prevalence of NAFLD reached $79.1 \%(95 \% \mathrm{Cl} 78.3-79.8)$ in obese subjects, $62.4 \%(95 \% \mathrm{Cl} 60.8-64.1)$ in type 2 diabetic subjects and 51.6\% (95\%Cl 50.6-52.5) in those with elevated ALT. When considering the combination of obesity, diabetes and/or ALT $>\mathrm{N}$ as risk factors, the NAFLD rate increased from $5 \%$ in patients having no risk factor to $96.9 \%$ in those having all 3 risk factors (Figure $1 B$ ). Geographic distribution of NAFLD in France showed a decrease in a North-South gradient.

General characteristics of NAFLD subjects are shown in Table 1. When adjusted on socio-economic status, independent parameters associated with NAFLD in obese and non-obese subjects were age (OR 1.02, 95\% $\mathrm{Cl}$ 1.01-1.03 and 1.02, 1.01-1.04 respectively), male gender (OR 5.7, 95\% $\mathrm{Cl}$ 5.0-6.6 and 7.5, 7.0-8.1), type 2 diabetes (OR 4, 95\%Cl 3.1-5.3 and 3.6, 3.2-4.1), high blood pressure (OR 1.7, $95 \% \mathrm{Cl} 1.5-2.0$ and $2.1,2.0-2.3$ ), hypercholesterolemia (OR 1.5, 95\% Cl 1.4-1.6 and 1.7, 1.6-1.7) and 
ALT above the normal threshold (OR 4.1, 95\% $\mathrm{Cl} 3.4-5.0$ and 6.5, 6.2-7.0). In non-obese subjects, North African ( $\mathrm{OR} 1.8,95 \% \mathrm{Cl} 1.6-2.1$ ) and Asian origins (OR 0.6, 95\% $\mathrm{Cl} 0.4-0.9$ ) were also independently associated with NAFLD.

FI was available in 16212 subjects with NAFLD (99\%). According to Fl> 6.9, the prevalence of advanced fibrosis among NAFLD subjects was $2.6 \%(95 \% \mathrm{Cl} 2.4-2.8)$, which corresponds to 220,776 $(95 \% \mathrm{Cl} 203,793-237,758)$ adult individuals when extrapolated to the general population of metropolitan France. Among risk groups with NAFLD, the rate of advanced fibrosis was $2.5 \%(95 \% \mathrm{Cl}$ 2.2-2.8) in obese subjects, $7.6 \%$ (95\%IC 6.5-8.7) in type 2 diabetic subjects and $3.8 \%(95 \% \mathrm{Cl} 3.3-4.3)$ in those with elevated ALT. When considering the combination of obesity, diabetes and ALT>N as risk factors, the prevalence of advanced fibrosis increased from $0.3 \%$ in NAFLD patients having no risk factor to $13.6 \%$ in those having all 3 risk factors. Characteristics of NAFLD subjects with advanced fibrosis are shown in Table 1. Independent risk factors of advanced fibrosis in NAFLD subjects were age, male gender, obesity, diabetes, HBP, elevated ALT and smoking (Table S1). 


\section{Discussion}

NAFLD affects almost $1 / 5$ of a large French adult population-based cohort with no excessive alcohol consumption or chronic viral hepatitis. To our knowledge, this is the largest European survey evaluating NAFLD and advanced fibrosis in the general population. The CONSTANCES populationbased cohort is a very large and representative survey of French general security regime (RG) affiliates aged 18 and over, representing approximately 50 million people (2). The lower prevalence of obesity or diabetes than expected in our study population (4) was partly explained by the exclusion of subjects with excessive alcohol consumption or viral hepatitis. NAFLD and advanced fibrosis were assessed by using validated non-invasive biomarkers ( 5 , Supplementary Methods).

As previously reported in the NHANES cohort, NAFLD prevalence was more than twice higher among men compared to women, increased with age, was strongly related with metabolic disorders or abnormal ALT, and was lower in Asian subjects $(6,7)$. The prevalence of advanced fibrosis was 3 times higher among NAFLD subjects with type 2 diabetes compared to other groups, confirming that diabetes is a major driver of fibrosis (8).

These data highlight that screening for NAFLD should be implemented in populations at risk, especially in subjects with diabetes. Preventive and therapeutic measures should be taken to reduce the impact of the disease in the population. 


\section{References}

1. Younossi ZM, Koenig AB, Abdelatif D, Fazel Y, Henry L, Wymer M. Global epidemiology of nonalcoholic fatty liver disease-Meta-analytic assessment of prevalence, incidence, and outcomes. Hepatololgy 2016; 64:73-84.

2. Zins $M$, Goldberg $M$, CONSTANCES team. The French CONSTANCES population-based cohort: design, inclusion and follow-up. Eur J Epidemiol 2015; 30: 1317-28.

3. Bedogni G, Bellentani S, Miglioli L, Masutti F, Passalacqua M, Castiglione A, et al. The Fatty Liver Index: a simple and accurate predictor of hepatic steatosis in the general population. BMC Gastroenterol 2006; 6: 33.

4. Matta J, Carette C, Rives Lange C, Czernichow S. French and worldwide epidemiology of obesity. Presse Med 2018; 47: 434-438.

5. Koehler EM, Schouten JNL, Hansen BE, Hofman A, Stricker BH, Janssen HLA. External validation of the fatty liver index for identifying nonalcoholic fatty liver disease in a population-based study. Clin Gastroenterol Hepatol 2013; 11: 1201-4.

6. Younossi ZM, Stepanova M, Younossi Y, Golabi P, Mishra A, Rafiq N, et al. Epidemiology of chronic liver diseases in USA in the pas three decades. Gut 2020; 69: 564-568.

7. Golabi P, Palk J, Hwang JP, Wang S, Lee HM, Younossi ZM. Prevalence and outcomes of non-alcoholic fatty liver disease (NAFLD) among asian american adults in the United States. Liver Int 2019; 39: 748757.

8. Koehler EM, Plompen EPC, Schouten JNL, Hansen BE, Darwish Murad S, Taimr P, et al. Presence of diabetes mellitus and steatosis is associated with liver stiffness in a general population: The Rotterdam study. Hepatology 2016; 63: 138-47 
Figure 1. (A) Distribution of NAFLD according to age and gender; (B) Prevalence of NAFLD according to the presence of obesity, type 2 diabetes and/or ALT $>N$. 
Table 1: General characteristics of overall population, NAFLD subjects (defined by a Fatty Liver Index>60) and NAFLD subjects with advanced fibrosis (defined by a Forns Index>6.9).

\begin{tabular}{|c|c|c|c|}
\hline & $\begin{array}{l}\text { Overall population } \\
\qquad n=102,344\end{array}$ & $\begin{array}{l}\text { NAFLD subjects } \\
n=16,273\end{array}$ & $\begin{array}{l}\text { NAFLD subjects with } \\
\text { advanced fibrosis } \\
n=422\end{array}$ \\
\hline Age, yrs, mean (SD) & $47.2(13.6)$ & $52.9(11.7)$ & $65(4.9)$ \\
\hline Male gender, \% (95\% Cl) & $45.4(45.1-45.7)$ & $66.8(66.1-67.5)$ & $92.9(90.5-95.4)$ \\
\hline Waist circumf., cm, mean (SD) & $84.6(12.9)$ & $103.7(9.2)$ & $107.3(9.5)$ \\
\hline Overweight, \% (95\% Cl) & $30.0(30.3-30.6)$ & $36.9(36.2-37.6)$ & $36.4(31.8-40.9)$ \\
\hline Obesity, \% (95\% Cl) & $12.3(12.1-12.5)$ & $61.2(60.4-61.4)$ & $59.9(55.2-64.5)$ \\
\hline Diabetes mellitus, \% (95\% Cl) & $3.7(3.7-3.9)$ & $13.6(13.2-14.2)$ & $47.2(42.5-52)$ \\
\hline High blood pressure,\% (95\% Cl) & $11.6(11.4-11.8)$ & $28.6(27.9-29.3)$ & $56.4(51.7-61.2)$ \\
\hline Hypertriglyceridemia,\% (95\% CI) & $12.5(12.3-12.7)$ & $44.9(44.1-45.7)$ & $42.6(37.9-47.3)$ \\
\hline $\begin{array}{l}\text { Hypercholesterolemia, } \%(95 \% \\
\text { CI) }\end{array}$ & $8.1(8.0-8.3)$ & $20.6(19.9-21.2)$ & $53.3(48.5-58)$ \\
\hline Metabolic syndrome,\% (95\% CI) & $13.4(13.2-13.6)$ & $59.8(59-60.6)$ & $80.8(77-84.5)$ \\
\hline GGT>N,\% (95\% CI) & $15.3(15.1-15.5)$ & $48(47.2-48.8)$ & $66.8(63.4-70.2)$ \\
\hline$A L T>N, \%(95 \% \mathrm{Cl})$ & $11.1(10.9-11.3)$ & $33.9(33.2-34.6)$ & $57.7(53-62.4)$ \\
\hline \multicolumn{4}{|c|}{$\begin{array}{l}\text { All comparisons between the } 3 \text { groups had a p value }<0.05 \text {, excepted overweight, obesity and } \\
\text { hypertriglyceridemia prevalence between NAFLD and NAFLD with advanced fibrosis groups. } \\
\text { Obesity was defined as BMI } \geq 30 \mathrm{~kg} / \mathrm{m}^{2} \text {, or } \geq 25 \mathrm{~kg} / \mathrm{m}^{2} \text { if Asian ethnicity, and overweight as BMI [25-29.9], or [23- } \\
24.9 \text { if Asian ethnicity. Abdominal obesity was defined according to the waist circumference } \geq 94 \mathrm{~cm} \text { for men ( } \geq 90 \\
\mathrm{~cm} \text { if Asian ethnicity) and } \geq 80 \mathrm{~cm} \text { for women. }\end{array}$} \\
\hline \multicolumn{4}{|c|}{$\begin{array}{l}\text { DM was defined by a blood glucose greater than } 6.9 \mathrm{mmol} / \mathrm{L} \text { after } 12 \text { hours fasting according to the WHO } \\
\text { definition and / or antidiabetic therapy. }\end{array}$} \\
\hline \multicolumn{4}{|c|}{$\begin{array}{l}\text { HBP was defined either on the basis of self-reporting and / or antihypertensive therapy and / or systolic blood } \\
\text { pressure } \geq 140 \mathrm{mmHg} \text { and/or diastolic } \geq 90 \mathrm{mmHg} \text {. }\end{array}$} \\
\hline
\end{tabular}


A

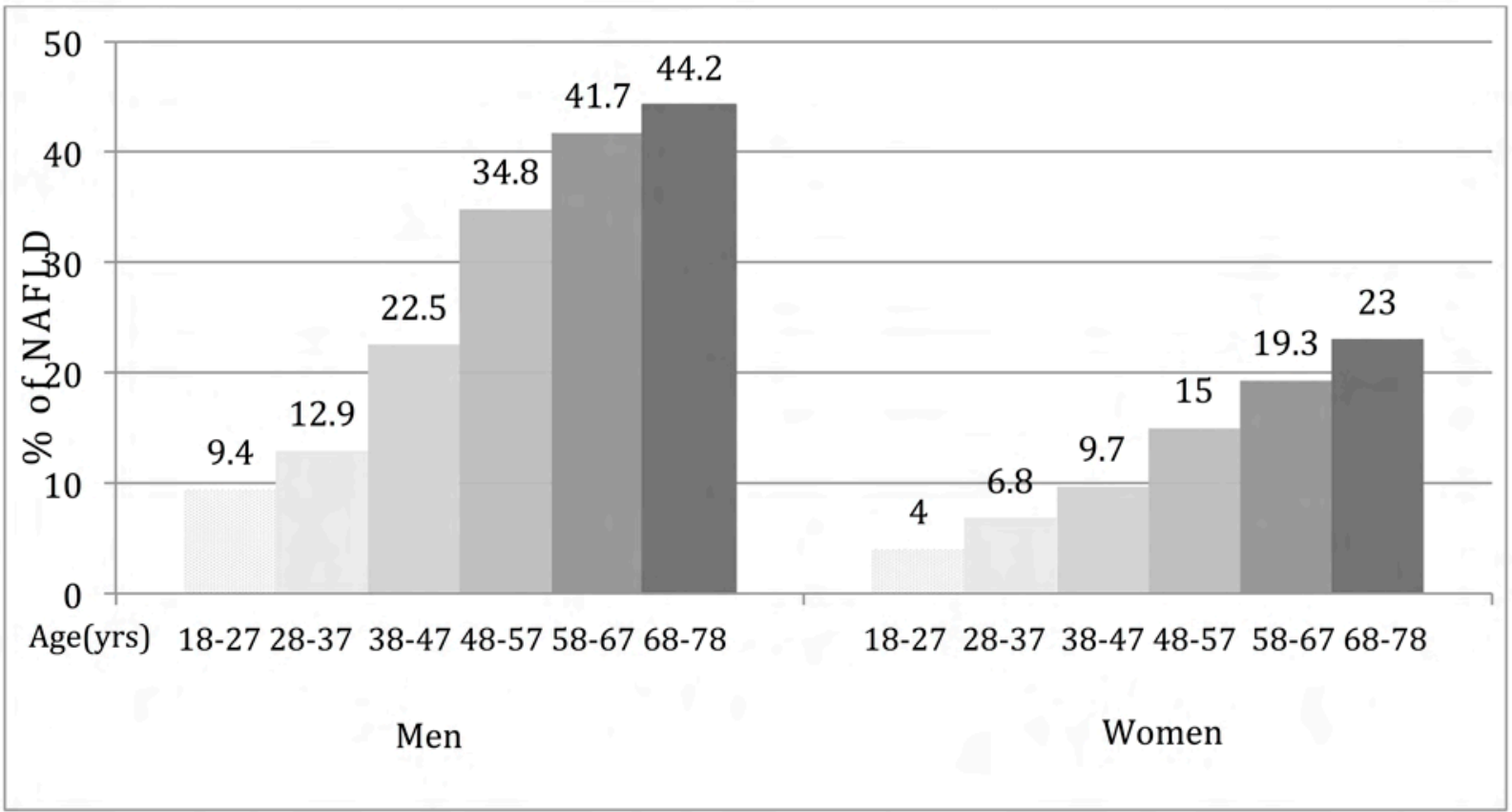

B

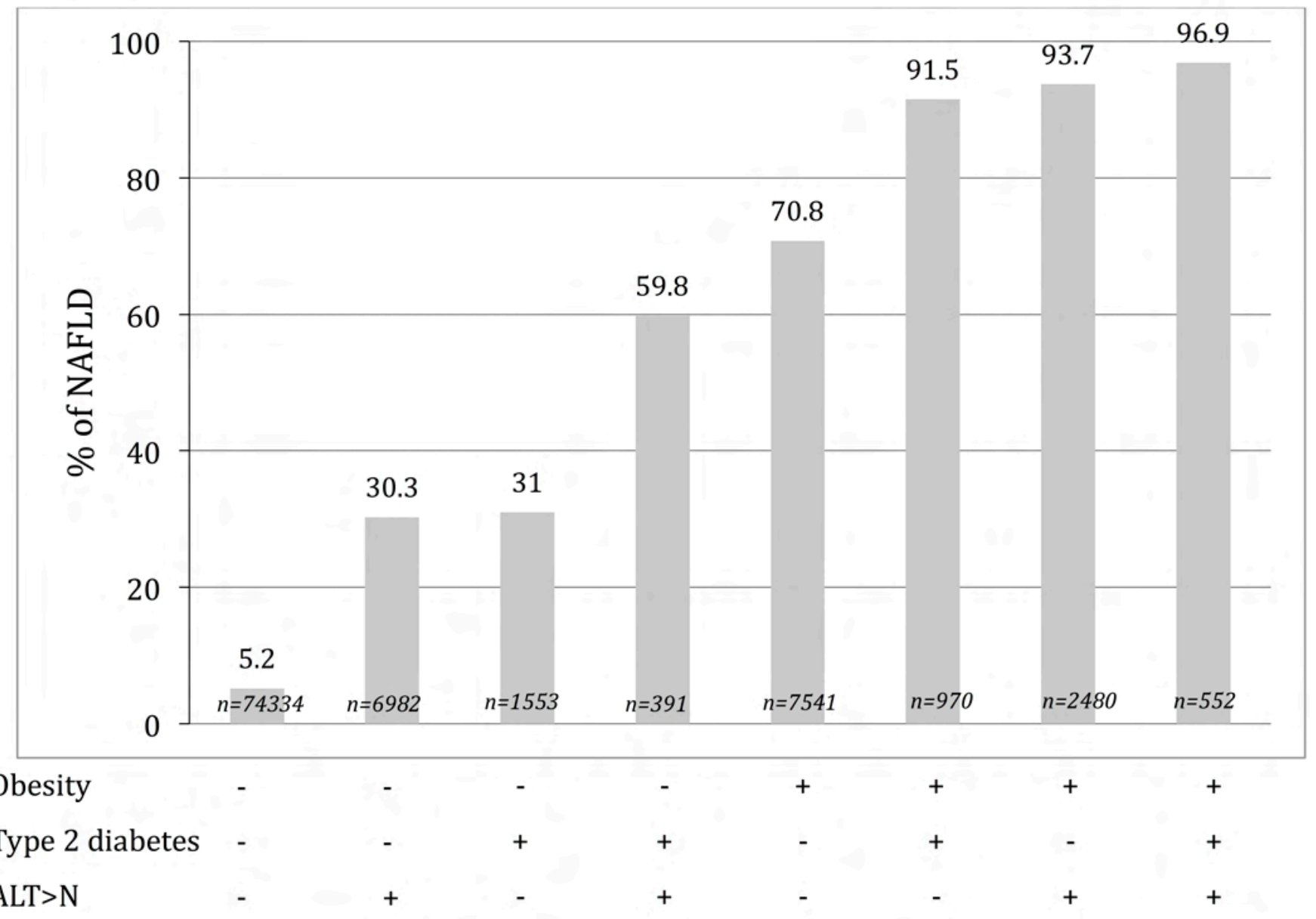

